ARTICLE HISTORY: Received: July 14, 2021 Accepted: September 6, 2021 Published: October 13, 2021

УДК 621.311.42: [621.316.925.1+621.314.222.6]

СОВРЕМЕННАЯ МИКРОПРОЦЕССОРНАЯ ЗАЩИТА СИЛОВЫХ ТРАНСФОРМАТОРОВ

Гусева А.И.

ФГАОУ ВО «Национальный исследовательский Нижегородский государственный университет им. Н.И. Лобачевского»

Арзамасский филиал

Отделение среднего профессионального образования

Россия, Арзамас

\title{
MODERN MICROPROCESSOR PROTECTION OF POWER TRANSFORMERS
}

\author{
Guseva A.I. \\ FGAOU VO "National Research \\ Nizhny Novgorod State University named after N.I. Lobachevsky" \\ Arzamas branch \\ Secondary Vocational Education Department \\ Russia, Arzamas
}

\begin{abstract}
Аннотация. Целью настоящего исследования было понять, какие плюсы и минусы в эксплуатации микропроцессорных устройство в РЗА, разобрать основные серии микропроцессорной защиты, их плюсы, минусы и особенности, сделать обзор микропроцессорной защиты на рынке труда. На основании этого сделать вывод об актуальности и приемлемости микропроцессорной защиты в целом.

В ходе исследования изучалось несколько компаний, которые занимаются микропроцессорной защитой. Сравнение микроконтроллеров является сложной задачей. Обычно каждый производитель кристалла предлагает свои, разработанные лично им, тесты, показывающие, что его микроконтроллер самый лучший. Поэтому их сравнение производилось также с учетом характеристик самих релейных защит на базе данных микропроцессоров.

Abstract. The purpose of the present study was to understand what advantages and disadvantages in the operation of microprocessor devices in the RZA, to analyze the main series of microprocessor protection, their advantages, disadvantages and features, to review microprocessor protection in the labor market. Based on this, conclude the relevance and acceptability of microprocessor protection in general.

The study examined several companies that are engaged in microprocessor protection. Comparing microcontrollers is challenging. Usually, each crystal manufacturer offers its own tests, developed personally by him, showing that its microcontroller is the best. Therefore, their comparison was also made taking into account the characteristics of the relay protections themselves based on microprocessor data.
\end{abstract}

Ключевые слова: автоматика, релейная защита, микропроцессор, микроконтроллер, силовой трансформатор.

Keywords: automation, relay protection, microprocessor, microcontroller, power transformer.

В наши дни микропроцессорные устройства релейной защиты являются одним из основных направлений развития релейной защиты. Помимо основной функции - аварийного отключения энергетических систем, они имеют добавочные функции по сравнению с устройствами релейной защиты других видов по регистрации аварийных ситуаций. Модернизация и развитие релейной защиты и автоматики в наши дни уже сложно обойтись без применения микропроцессорной техники.

Релейная защита родилась и развивалась на базе механических устройств, которые постепенно усложнялись до существующих сегодня многофункциональных механических комплексов. Примерно три десятилетия назад с развитием электронной промышленности появились устройства защиты на полупроводниковых элементах. Они не вытеснили полностью своих механических собратьев и до сегодняшнего дня эксплуатируются вместе с ними.

Около 15 лет назад в энергетике стало массово внедряться новое оборудование для защиты объектов энергоснабжения, использующее компьютерные технологии на базе процессоров. Его стали называть сокращенным термином МУРЗ - микропроцессорные устройства релейной защиты.

Они выполняют функции обыкновенных устройств РЗА на основе новой элементной базы микроконтроллеров (микропроцессорных элементов). 
Микроконтроллер - это специальная микросхема, предназначенная для управления различными электронными устройствами. Микроконтроллеры впервые появились в том же году, что и микропроцессоры общего назначения (1971). На сегодняшний день существует более 200 модификаций микроконтроллеров, выпускаемых двумя десятками компаний, и большое количество микроконтроллеров других типов.

Микроконтроллер характеризуется большим числом параметров, поскольку он одновременно является сложным программно-управляемым устройством и электронным прибором (микросхемой). Приставка "микро" в названии микроконтроллера означает, что выполняется он по микроэлектронной технологии.

В ходе работы микроконтроллер считывает команды из памяти или порта ввода и исполняет их. Что означает каждая команда, определяется системой команд микроконтроллера. Система команд заложена в архитектуре микроконтроллера и выполнение кода команды выражается в проведении внутренними элементами микросхемы определенных микроопераций.

Микроконтроллеры позволяют гибко управлять различными электронными и электрическими устройствами. Некоторые модели микроконтроллеров настолько мощны, что могут непосредственно переключать реле.

Микроконтроллеры, как правило, не работает в одиночку, а запаивается в схему, где, кроме него, подключаются экраны, клавиатурные входы, различные датчики и т.д.

Микроконтроллеры интегрируют в себе технические возможности для обработки смешанных сигналов и вычислительную мощность, при этом уровень производительности МК и их функционал постоянно растет. Однако существуют другие разработки, которые позволяют продлить жизненный цикл бюджетных и низкопроизводительных микроконтроллеров.

По определению, микроконтроллеры бесполезны без связи с «реальным миром». Они были разработаны, чтобы действовать в качестве концентраторов для входов и выходов, выполняя задачи условных переходов и управляя последовательными и параллельными процессами. Их роль определяется управлением, в то время как возможность программирования означает, что характер управления задается логикой. Тем не менее, они изначально разрабатывались с целью получить интерфейс для аналогового мира, и, следовательно, в своей работе микроконтроллеры существенно опираются на процесс аналого-цифрового преобразования. Часто это цифровое представление аналогового параметра, обычно получаемого от какого-то датчика, на основе которого строится процесс управления, и основное применение микроконтроллера в таком случае видится в системах автоматизации. Способность управлять большими и сложными механическими системами, используя миниатюрный и относительно дешевый «кусочек» кремния, способствовало тому, что микроконтроллеры стали самым важным элементом промышленных систем автоматизации, и не удивительно, что многие производители стали выпускать специализированные семейства микроконтроллеров.

Обобщённая структурная схема типового микропроцессора показана на Рис. 1. В его основе — центральное процессорное устройство (ЦПУ), которое содержит арифметический вычислитель, логическое ядро и регистры общего назначения. С внешним миром ЦПУ общается при помощи трёх шин: адреса, данных и управления.

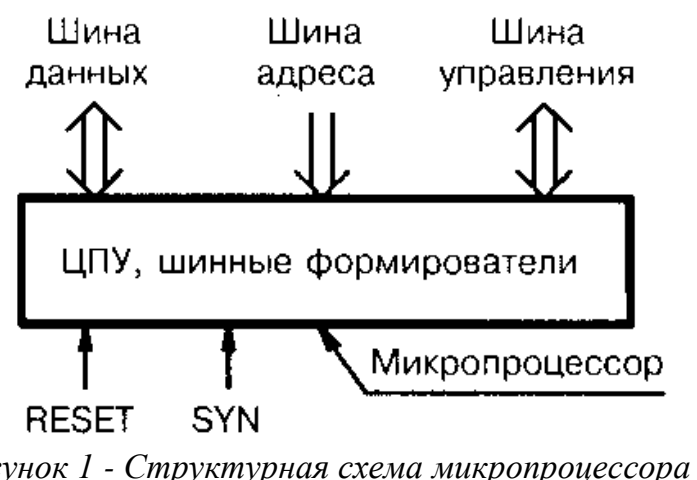

Если к ЦПУ на кристалл добавить оперативное и постоянное запоминающие устройства (ОЗУ, ПЗУ), таймеры, счётчики, аналого-цифровые и цифро-аналоговые преобразователи (АЦП, ЦАП), интерфейсные узлы и порты ввода/вывода, то микропроцессор превратится в микроконтроллер (рис. 2). 


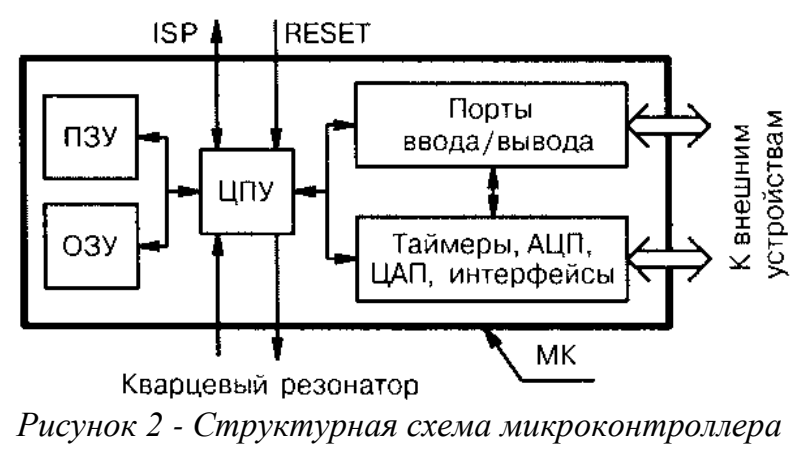

Сегодня на рынке микропроцессорных реле защиты (далее - МУР3) присутствуют сотни моделей десятков различных производителей. В соответствии с данными отчета Newton-Evans Research Co. в 2006 году группой ведущих компаний мира: ABB, Areva, SEL, Siemens, NARI было продано реле защиты на сумму около 950 миллионов долларов, а второй группой, в которую вошли Basler, General Electric, Schneider - еще на 500 миллионов. Помимо указанных в отчете, на рынке МУРЗ сегодня активно работают такие крупные компании, как Beckwith, Cooper Power, Orion Italia, VAMP, Woodward и др. По данным того же отчета в 2009 году ожидается продажа реле защиты Западными компаниями на сумму уже 2 миллиарда долларов. Рынок России и других стран бывшего СССС представлен как крупными Западными производителями, так и местными: НПП Бреслер, НПП "Экра", РЕЛСіС, Киевприбор, ЗАО «Меандр», НТЦ «Механотроника», ЗАО «Радиус Автоматика», Энергомашвин, ЗАО ЧЕАЗ, ВНИИР, и др. (см. рис.3)

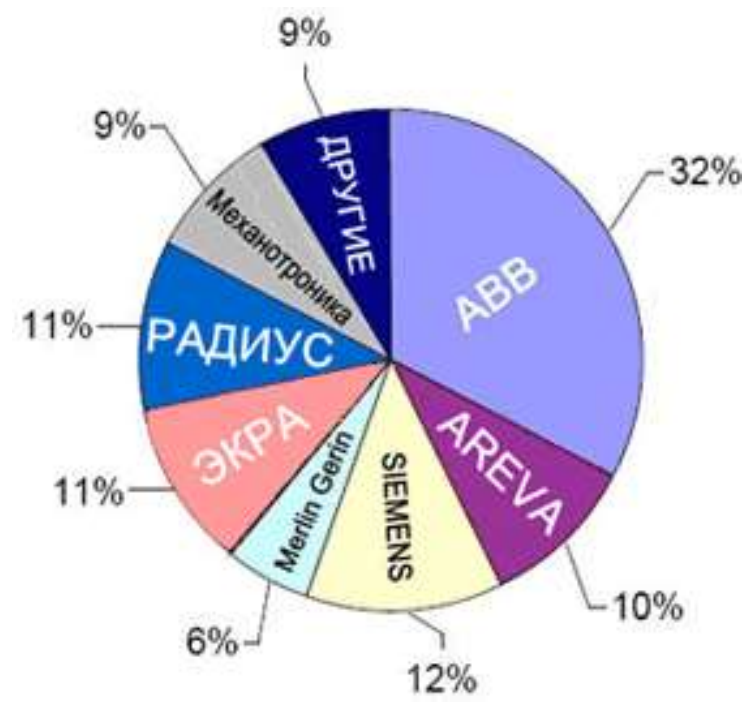

Рисунок 3 -

При таком многообразии производителей и типов МУРЗ, представленных на рынке, потребитель всегда может выбрать наиболее подходящий для него вариант МУРЗ и никаких проблем с этим у него быть не должно.

Основное преимущество микропроцессорных терминалов защит оборудования - то их многофункциональность. Помимо основных функций, а именно реализации защиты оборудования и работы автоматических устройств, микропроцессорные терминалы осуществляют замер электрических величин. Если взглянуть на старые панели защит оборудования подстанции, то мы увидим множество реле и аналоговых измерительных приборов. В случае использования микропроцессорных защит необходимость установки дополнительных измерительных приборов отсутствует, так как значения основных электрических величин можно фиксировать на ЖК-дисплее терминалов защит. Тут можно отметить еще одно преимущество - точность измерения. Аналоговый прибор позволяет измерить величину с определенной погрешностью, а если приборы служат не один десяток лет, то их точность существенно снижается, да и фиксировать показания не всегда удобно. На дисплее терминала указываются точные значения электрических величин и что немаловажно пофазно. Это позволяет контролировать отключенное положение всех полюсов выключателей. Исходя из вышесказанного, можно выделить еще одно преимущество микропроцессорных защит - компактность.

При использовании микропроцессорных технологий общее количество панелей для защит, автоматики и управления оборудованием, установленных общеподстанционном пункте управления, сокращается буквально 
вдвое. Если, например, для защиты, работы автоматических устройств, выключателями силового трансформатора устанавливалось три панели с электромеханическими защитами, то в случае использования микропроцессорных защит все необходимые функции выполняет небольших терминала, установленных на одной панели.

Существенный недостаток микропроцессорных устройств - их высокая стоимость. Кроме того, существенные расходы предприятия выделяются на обслуживание микропроцессорных устройств: необходимо наличие дорогостоящего оборудования, программного обеспечения, а также специалистов с соответствующей квалификацией. Недостаток в дорогостоящем обслуживании микропроцессорных устройств не является существенным в том случае, если все подстанции предприятия укомплектованы современными микропроцессорными техниками. В данном случае обслуживанием данных устройств занимается служба релейной защиты и автоматики, которая специализируется исключительно на данных типах защитных устройств. Если же микропроцессорные защиты установлены на нескольких объектах, то это действительно дорого обходится предприятию, так как возникает необходимость содержания специалистов нескольких служб для обслуживания, как микропроцессорных устройств, так и традиционных, электромагнитных. Еще один недостаток микропроцессорных устройств - узкий диапазон рабочих температур. Традиционные защитные устройства, выполненные на обычных реле, достаточно неприхотливы и могут работать в широком диапазоне рабочих температур. В то время как для обеспечения корректной работы микропроцессорных устройств необходимо устанавливать дополнительное климатическое оборудование. Следует отметить такой недостаток микропроцессорных устройств, как периодические сбои в программном обеспечении. Не смотря на заявления производителей микропроцессорных защит об их стабильной работе, очень часто наблюдается сбой в работе программного обеспечения (например, периодическая перезагрузка терминала).

Если в момент сбоя программного обеспечения произойдет короткое замыкание, то это может привести к повреждению оборудования, так как в этот момент присоединение находится без защиты. На фоне многочисленных преимуществ микропроцессорных устройств, их недостатки не столь существенны, а в некоторых случаях могут быть исключены. Например, установка надежного программного обеспечения и обеспечение оптимальных условий работы микропроцессорных устройств, возникновение ошибок или сбоев в их работе.

\section{ЛИТЕРАТУРА}

1. Барабанов, Ю.А. Микропроцессорные устройства релейной защиты и автоматики распределительных сетей / Ю.А. Барабанов. - Вологда: Инфра-Инженерия, 2015. - 172 с.

2. Гуревич, В.И. Уязвимость микропроцессорных реле защиты: проблемы и решения / В.И. Гуревич. Вологда: Инфра-Инженерия, 2014. - 256 с.

3. Гуревич, В.И. Микропроцессорные реле защиты. Устройство, проблемы, перспективы / В.И. Гуревич. М.: Инфра-Инженерия, 2011. - 336 с.

4. Гусев, В.Г. Электроника и микропроцессорная техника: Учебник / В.Г. Гусев, Ю.М. Гусев.. - М.: КноРус, 2013. - $800 \mathrm{c}$.

5. Калашников, В.И. Электроника и микропроцессорная техника: Учебник для студ. учреждений высш. проф. обр. / В.И. Калашников, С.В. Нефедов. - М.: ИЦ Академия, 2012. - 368 с.

6. Смирнов, Ю.А. Основы микроэлектроники и микропроцессорной техники: Учебное пособие / Ю.А. Смирнов, С.В. Соколов, Е.В. Титов. - СПб.: Лань, 2013. - 496 с.

7. Шагурин, И.И. Современные микроконтроллеры и микропроцессоры фирмы Motorola: Справочник. / И.И. Шагурин. - М.: Горячая линия -Телеком , 2004. - 952 с.

8. Евдокимов Ф.Е. Теоретические основы электротехники. М., Высшая школа. 1994.

9. Киреева, Э. А. Релейная защита и автоматика электроэнергетических систем / Э.А. Киреева, С.А. Цырук. - М.: Академия, 2013. - 288 с.

1. Drums, Yu.A. Microprocessor devices of relay protection and automation of distribution networks/Yu.A. Drabanov. - Vologda: Infra-Engineering, 2015. - 172 c.

2. Gurevich, V.I. Vulnerability of microprocessor protection relays: problems and solutions/V.I. Gurevich. Vologda: Infra-Engineering, 2014. - 256 c.

3. Gurevich, V.I. Microprocessor protection relays. Device, problems, prospects/V.I. Gurevich. - M.: InfraEngineering, 2011. - $336 \mathrm{c}$.

4. Gusev, V.G. Electronics and microprocessor technology: Textbook/V.G. Gusev, Yu.M. Gusev.. M.: KnoRus, 2013. - 800 c.

5. Kalashnikov, V.I. Electronics and microprocessor technology: Textbook for students of higher institutions. Prof. arr ./V.I. Kalashnikov, S.V. Nefedov. - M.: IC Academy, 2012. - 368 c.

6. Smirnov, Yu.A. Fundamentals of microelectronics and microprocessor technology: Textbook/Yu.A. Smirnov, S.V. Sokolov, E.V. Titov. - St. Petersburg: Lan, 2013. - 496 c. 
7. Shagurin, I.I. Modern microcontrollers and microprocessors from Motorola: Reference book ./I.I. Shagurin. - M.: Hotline -Telecom, 2004. - $952 \mathrm{c}$.

8. Evdokimov F.E. Theoretical foundations of electrical engineering. M., High School. 1994.

9. Kireeva, E. A. Relay protection and automation of electric power systems/E.A. Kireeva, S.A. Tsyruk. M.: Academy, 2013. - 288 c. 